\title{
Ensino e aprendizagem de língua inglesa e recursos tecnológicos: um estudo sobre os processos de retroação e irreversibilidade
}

\author{
Teaching and learning of the English language and technological resources: a \\ study about the processes of feedback and irreversibility
}

\section{Larissa de Sousa Silveira*}

\begin{abstract}
Resumo: Crystal (2003) ressalta a importância da Língua Inglesa ao classificá-la como a língua universal utilizada por milhões de falantes ao redor do mundo. Partindo desse pressuposto, propusemo-nos a pesquisar sobre o processo de ensino e aprendizagem dessa língua e a importância dos recursos tecnológicos no contexto formal e informal de aprendizagem. Objetivamos ainda entender como as atitudes dos professores podem influenciar de maneira negativa no desenvolvimento do interesse dos alunos pela disciplina, interrompendo o processo natural de Retroação (BERTALANFFY, 1975) ao qual eles são submetidos. Para tanto, utilizamos como base teórica as premissas do Paradigma da Complexidade (HOLLAND, 1998; DEMO, 2002). Os dados foram coletados em uma escola pública municipal de Uberaba/MG através de observações, anotações e aplicação de um questionário. Após as análises, concluímos que a interrupção do processo tende a acontecer quando o aprendiz sente a falta de incentivo por parte daquele que deveria ser seu maior incentivador na busca por novos conhecimentos. Concluímos ainda que o educador deve trabalhar como um mediador para auxiliar os alunos no reconhecimento das novas tecnologias digitais como inerentes ao processo de aquisição de conhecimento.
\end{abstract}

Palavras-chave: Língua Inglesa; processo de ensino e aprendizagem; recursos tecnológicos; Paradigma da Complexidade.

Abstract: Crystal (2003) emphasizes the importance of English Language when classified as the universal language used by millions of speakers around the world. Based on this assumption, we have proposed to research about the teaching and learning process of the English Language and the importance of technological resources in the formal and informal contexts of learning. We still aim to understand how the attitudes of teachers can influence negatively the development of students' interest in the subject, interrupting the natural process of feedback (BERTALANFFY, 1975) to which they are submitted. As theoretical basis, we used Paradigm of Complexity's premises (HOLLAND, 1998; DEMO, 2002). The data were collected in a public school of Uberaba / MG through observations, notes and application of a questionnaire. After the analysis, we have concluded that the interruption of the process tends to happen when the learner feels the lack of motivation from the professional who should be his/her greatest supporter in the search for new knowledge. We have also concluded that the educator must work as a mediator to assist students in the recognition of the new digital technologies as inherent to the process of knowledge acquisition.

Keywords: English Language; teaching and learning process; technological resources; Paradigm of Complexity.

\footnotetext{
* Graduada em Letras - Português/Inglês pela Universidade Federal do Triângulo Mineiro.
} 


\section{Introdução}

Atualmente a Língua Inglesa se configura como a primeira língua para milhões de pessoas ao redor do mundo, além de ser considerada também como segunda língua para muitos outros falantes (CRYSTAL, 2003). Nesse sentido, entendemos que o ensino dessa língua nas escolas regulares é muito relevante para a vida dos alunos e deve, portanto, ser oferecido de maneira atraente, despertando assim um maior interesse pela aprendizagem.

Partindo da afirmação de Crystal (2003), e do pressuposto de que o ensino de Língua Inglesa é relevante para a vida dos aprendizes, iniciamos este artigo com um relato da inquietação que foi base para a pesquisa. Em aulas de observação, durante o estágio de Língua Inglesa nas séries finais do Ensino Fundamental de uma escola municipal de Uberaba, alguns fatos recorrentes chamaram a atenção. Em quase todas as aulas, certos alunos traziam palavras, frases ou expressões de jogos ou sites da internet para que a professora pudesse traduzir e explicar o sentido mais pertinente. No entanto, na maioria das vezes, a professora não respondia ou simplesmente ignorava as perguntas causando um aparente desinteresse nos aprendizes. Em certos momentos, essa atitude se dava por falta de conhecimento de algumas palavras específicas dos jogos ou páginas da internet, mas, além disso, percebíamos negligência por parte da professora que não demonstrava interesse por pesquisar o sentido das expressões e/ou palavras.

Quando dizemos que o processo de ensino e aprendizagem de Língua Inglesa deve ser atraente para os alunos, estamos fazendo referência à inserção das novas tecnologias digitaís de informação e comunicação nas aulas e à atualização do educador em relação a isso. Tal inserção parece ser relevante para o bom andamento do processo e pretendemos mostrar isso através dos resultados desta pesquisa. Justificamos, portanto, a realização deste trabalho pela necessidade de dar voz aos alunos para que eles próprios possam indicar que a utilização de recursos tecnológicos é importante no contexto informal de aprendizagem de Língua Inglesa e que a integração desses recursos na sala de aula poderia tornar o processo de ensino e aprendizagem formal menos árduo.

Pretendemos, ainda, demonstrar que o andamento natural do processo de retroação ao qual o aprendiz é submetido tende a ser interrompido. Isso, devido à falta de reconhecimento por parte do educador em relação à autonomia e iniciativa do aluno em aprender a língua através da internet. Assim, ao final deste artigo, objetivamos 
responder a seguinte pergunta de pesquisa: Como a falta de incentivo, por parte do professor, à autonomia e à iniciativa do estudante de Língua Inglesa para aprender por meio da internet tende a interromper o processo natural de retroação?

Ressaltamos também que o processo de ensino e aprendizagem de Língua Inglesa se configura como um "sistema adaptativo complexo", ao mesmo tempo caótico e estruturado (DEMO, 2002). Nesse sentido, a característica da irreversibilidade faz-se presente no sistema como uma propriedade entrópica, à medida que o professor oferece condições iniciais ao aluno que podem ou não dinamizar a aprendizagem; a falta de dinamicidade pode causar desinteresse pela aprendizagem, o que talvez seja irreversível dependendo do nível de insatisfação do aluno em relação às aulas ou âs atitudes do professor.

O Grupo de Estudos em Linguagem e Educação Digital (GELED), do qual fazemos parte, se reúne para discussões sobre questões relacionadas à inserção das novas tecnologias no contexto de ensino-aprendizagem de Língua Inglesa. Barcelos (2010) em seu trabalho "Aprendendo inglês em jogos on-line: um relato sobre nativos digitais", obteve duas conclusões importantes: a primeira foi que os alunos do ensino médio de uma escola pública de Uberaba/MG não conseguiam estabelecer uma relação entre a aprendizagem de Língua Inglesa e o uso dos recursos tecnológicos, mesmo reconhecendo a existência da mesma; a segunda teve como foco um aluno, especificamente, que se destacava dos demais colegas da sala, por estar em contato constante com um jogo que exigia a utilização da Língua Inglesa como meio de comunicação.

Partindo dessas conclusões, percebemos a forte influência que o meio tecnológico exerce sobre os aprendizes e sobre o processo de internalização da Língua Inglesa. Com isso, apontamos que a intenção de nossa pesquisa é trazer fatos que complementem os trabalhos já desenvolvidos na área. Pretendemos ainda mostrar que a primeira consideração apontada por Barcelos (2010) não pode ser entendida de maneira generalizada, pois existem alunos que reconhecem a influência da tecnologia em sua aprendizagem, tanto que sentem falta de sua presença em sala de aula. O grande problema está no fato de os professores em geral, muitas vezes, não incentivarem a autonomia do aluno para utilização dos recursos tecnológicos digitais a seu favor, ou seja, para seu processo de aprender. Mesmo que a tecnologia não faça parte da formação profissional desses professores, ela deve fazer parte de sua prática docente. Essa prática 
deve acompanhar os avanços da modernidade. Se a formação inicial não consegue suprir as necessidades de aprendizagem do aluno, os professores devem se submeter a uma formação continuada.

Acreditamos que a contribuição mais relevante de nosso trabalho será a demonstração de como uma atitude do professor pode influenciar o nível de interesse do aluno na aprendizagem de Língua Inglesa. Para tanto, com autorização dos pais ou responsáveis, aplicamos um questionário aos alunos a fim de coletar respostas mais concretas, selecionamos as mais relevantes e obtivemos algumas conclusões, as quais serão apresentadas posteriormente. Todo o trabalho tem como base teórica premissas da Teoria da Complexidade (HOLLAND, 1998; DEMO, 2002).

\section{Fundamentação Teórica}

\subsection{Sala de aula: um sistema adaptativo complexo}

Partimos da ideia de Holland (1998) sobre Sistema Adaptativo Complexo (SAC) para discorrermos a respeito do caos estruturado da sala de aula. Trata-se de um espaço permeado pela não linearidade e pela desordem, mas que pode alcançar momentos de ordem, ou seja, manter os fluxos naturais entre caos e ordem, a partir de ações e interferências por parte do professor. $\mathrm{O}$ caos no contexto da sala de aula pode estar associado a diferentes fatores como: indisciplina por parte dos alunos, dificuldade na resolução de exercícios, desrespeito com o professor, desinteresse pela matéria apresentada, dentre outros ligados à relação aluno-professor e que podem atrapalhar a tranquilidade da aula.

Dizemos que o sistema é adaptativo pelo fato de que o caos que nele se estabelece não perdura de maneira irreversível. Os momentos de ordem em uma sala de aula podem ser atingidos, mas, para que isso aconteça, o profissional responsável por este ambiente precisa estar preparado para lidar com a imprevisibilidade dos acontecimentos. Essa imprevisibilidade envolve a interferência de fatores externos, inclusive a influência das novas tecnologias digitais no ensino e aprendizagem de Língua Inglesa, o que exige preparo, conhecimento e, principalmente, discernimento dos professores da área sobre o que é apropriado ou não para o contexto da sala de aula e sobre o que pode agregar alguma contribuição para o processo de ensino e aprendizagem 
Ao dizer que o sistema é complexo, estamos fazendo referência a certas características que lhes são peculiares, como dinamicidade, não-linearidade, imprevisibilidade, as quais definimos nos parágrafos que se seguem. É complexo devido à natureza de conexões entre as partes e o todo que conforma a sala de aula,

A dinamicidade implica constantes mudanças no sistema, cujos acontecimentos futuros dependem diretamente do que se desenvolve no tempo presente (LARSENFREEMAN; CAMERON, 2008). Em um sistema complexo como a sala de aula, não são apenas os agentes que se modificam, mas também as interações estabelecidas entre eles. Isso significa que não é possível prever as atitudes dos professores e dos alunos e nem mesmo se a interação entre eles será positiva ou negativa para o processo de ensino e aprendizagem. Podemos dizer ainda que essa imprevisibilidade encontra-se em duas direções: quando o aluno pergunta algo ao professor prevendo que ele saiba e esse não tem a resposta e quando, em meio à aula, o professor é surpreendido por uma pergunta do aluno que foge a tudo o que fora estruturado e planejado por ele.

A característica da não-linearidade é resultado dá dinamicidade que permeia o sistema e demonstra que na sala de aula os acontecimentos surgem de maneira imprevisível e nunca de maneira sequencial. Em um sistema não linear, os elementos não são independentes e as relações entre eles mudam a todo o momento, comprovando que não é possível haver uma ação previamente estabelecida para a prática do professor em sala de aula, a não ser que a previsão dos acontecimentos esteja somente no campo da abstração. Nesse sentido, o professor deve estar preparado para os desafios que possam surgir durante o desenvolvimento de todo o processo. Com a consciência de que na sala de aula poderão haver emergências na forma de perguntas que ele, possivelmente, não saberá responder no momento, mas que podem ser solucionadas posteriormente após alguma pesquisa ou conversa com os próprios alunos. Isso, além de agregar conhecimento ao professor, estreita os laços de proximidade com o aluno que passa a ter ciência de que aquela pessoa à frente da sala de aula não é absolutamente superior e inatingível.

Outro importante ponto a ser discutido é a questão da irreversibilidade no ambiente da sala de aula. Sobre isso Demo (2002) disserta que "o tempo é produtivo e desgastante, avança, mas não tem lugar certo para chegar, vai para frente, mas não tem ponto final, não pode retroceder, mas seu futuro depende muito do passado." (grifo nosso, p.24-25). Isso significa que é impossível voltar ao passado e que atitudes por 
parte do professor podem afetar o cotidiano escolar, e, consequentemente, o aluno de maneira irreversível. E isso, mais uma vez, demonstra a complexidade presente na sala de aula e transportada para o processo de ensino e aprendizagem. Assim como sugere a proposta do Efeito Borboleta ${ }^{1}$, na Educação também um pequeno detalhe pode afetar de maneira marcante o futuro do aluno ou do professor.

Larsen-Freeman (1997), ao escrever sobre sistemas complexos e a aquisição de uma segunda língua, nos explica que existem duas razões para que um sistema seja chamado de complexo; a primeira diz respeito ao grande número de agentes presentes no mesmo ambiente e a segunda faz referência à ação desses agentes que não acontece de maneira individual e isolada. Em um sistema complexo, seus componentes interagem uns com os outros, provocando ações e reações constantes, alem da emergência de fenômenos nem sempre previstos.

Os sistemas fechados tendem a mover-se para o equilíbrio que uma vez atingido, não se desfaz (LARSEN-FREEMAN, 1997). Mas esse postulado apenas se aplica aos sistemas fechados. Quanto aos sistemas abertos, como a sala de aula, podemos dizer que o equilíbrio não é constante, principalmente devido à interferência de fatores externos. $\mathrm{O}$ fato de ser aberto exige do sistema que ele seja adaptativo o que implica na capacidade de se auto-organizar. No caso da sala de aula, a interação entre os principais agentes (alunos e professor), quando bem sucedida, pode ser a responsável pelo estabelecimento de momentos de equilíbrio.

Dentro do complexo contexto da sala de aula, outro sistema caótico se estabelece. Trata-se do processo de aprendizagem de uma segunda língua. Toda a complexidade presente nesse sistema exige que o aprendiz seja visto como um indivíduo autônomo, capaz de interagir com os demais agentes e, ainda, apto a contribuir no desenvolvimento do seu processo. Entretanto, muitos professores têm dificuldade em aceitar essa nova realidade. Isso acontece porque eles continuam a considerar a internalização de conhecimento como um processo linear em que "o professor fala, o aluno escuta, toma nota e devolve na prova" (DEMO, 2002, p.124).

\footnotetext{
${ }^{1}$ O meteorologista Edward Lorenz (1963) desenvolveu um dos estudos que mais influenciou a Teoria do Caos. Em uma tentativa de previsão meteorológica, percebeu que sistemas não-deterministas eram sensíveis à condições iniciais e concluiu que pequenas diferenças nessas condições iniciais poderiam implicar em diferenças significativas nos resultados. Essa conclusão ficou conhecida como "efeito borboleta".
} 
Demo (2002), ainda completa, pontuando que "na relação dinâmica não linear, a relação pedagógica supõe dois sujeitos autônomos em interação naturalmente criativa, desafiadora e provocativa, eivada de negociações e pretensões de ambos os lados, em grande parte imprevisível" (p.137). Como bem aponta o autor, supõe-se a existência de sujeitos autônomos no processo dinâmico e não linear de aprendizagem, mas essa suposição muitas vezes não é efetivada, já que o aluno nem sempre reúne os requisitos necessários para ser considerado autônomo e o professor nem sempre incentiva o desenvolvimento dessa autonomia em sala de aula. Tais fatores juntos, muitas vezes, conseguem impedir o andamento eficaz da aquisição de conhecimento, pois inibem a “interação criativa e provocativa" entre professor e aluno, essencial para o desenvolvimento de uma consciência crítica.

A ideia que ainda se mantém hoje em dia é a de que uma língua apenas pode ser adquirida em um contexto formal de aprendizagem, no qual o professor encontra artifícios para efetivar sua prática. No entanto, segundo Paiva (2009, p. 192),

podemos prever que em contextos formais de aprendizagem os alunos vão ser capazes de memorizar regras e vocabulário, mas não podemos prever se todos eles vão adquirir a língua, isto é, se eles vão se engajar em práticas sociais da linguagem mediada pela língua estrangeira.

Oliveira (2011) em seu trabalho intitulado "De redes sociais a comunidades de prática: um estudo sobre percepção e efetivação de affordances no ambiente on-line" realizou uma pesquisa com 43 (quarenta e três) participantes, dos quais 39 (trinta e nove) demonstraram perceber a importância do contexto on-line informal para a aprendizagem de Língua Inglesa. Alguns deles não só percebem as oportunidades propiciadas por esse ambiente, como também aproveitam para se beneficiar, aperfeiçoando o idioma que estão aprendendo. Com isso, entendemos que da mesma forma que existem alunos capazes de aprender a língua apenas em contextos formais de aprendizagem, existem aqueles que tendem a procurar meios informais que facilitem ou complementem o processo de aprendizagem da segunda língua pretendida.

Ainda discorrendo a respeito de sistemas adaptativos complexos, devemos citar um conceito que será importante para as análises que faremos posteriormente. Trata-se do conceito de Retroação que, na teoria de Bertalanffy (1975) significa "conservação 
homeostática $^{2}$ de um estado característico ou a procura de uma meta, baseada em cadeias causais circulares e mecanismos que enviam retroativamente a informação sobre os desvios do estado a ser mantido ou da meta a ser atingida." (p.72).

Ampliando os conceitos de Retroação, podemos citar Rosini (2006) que pressupõe a existência de uma "curva de retroação (feedback)" que substitui a causalidade linear pela causal. As principais funções da retroação são controlar a saída do sistema e manter seu equilíbrio e sua sobrevivência. Seu conceito compreende, portanto, as características de um sistema complexo, já abordadas anteriormente, devendo ser considerado nas análises posteriores.

No processo de ensino e aprendizagem de uma segunda língua como a Língua Inglesa, os agentes da Retroação são o aluno e o professor que estabelecem troca de informações e são os responsáveis por permitir a continuidade circular do processo, o ato de um influencia a reação do outro e vice-versa. Mais adiante, veremos como isso acontece em sala de aula e como a interrupção desse processo pode ser prejudicial para a aprendizagem de uma língua estrangeira.

\subsection{Contexto informal de aprendizagem: a influência das novas tecnologias digitais no processo de ensino e aprendizagem de Língua Inglesa}

Com a rápida disseminação das novas tecnologias nos últimos anos, torna-se impossível não discutir sobre esse assunto quando falamos a respeito do processo de ensino e aprendizagem que enyolve, principalmente, as crianças e os adolescentes. Eles fazem parte da chamada nova geração digital e preferem, claramente, jogos on-line e internet a qualquer trabalho "sério" proposto no contexto escolar formal.

Segundo Prensky (2001), existem os "nativos digitais" e os "imigrantes digitais". Em suma, o autor defende que os primeiros representam aqueles que já nascem no mundo digital e, portanto, o dominam facilmente; os imigrantes são os que nasceram em épocas anteriores, mas que demonstram interesse pelas novas tecnologias.

De acordo com Carlini e Leite (2010), o nativo digital é "alguém que tomou consciência de si em um ambiente social permeado por tecnologias" (p. 27). Trata-se, portanto, de "um ser humano com habilidades especiais para utilizar recursos tecnológicos" (p. 27).

\footnotetext{
${ }^{2}$ Para a Biologia, a homeostasia é um processo de regulação pelo qual um organismo mantém constante o seu equilíbrio. Para a Fisiologia, é o estado de equilíbrio das diversas funções e composições químicas do corpo.
} 
No ambiente da sala de aula, encontramos exemplos para ambas as classificações. Os alunos podem ser considerados os nativos e o professor, o imigrante digital. Mas isso apenas em relação à diferença entre gerações, pois podem existir alunos que não possuem familiaridade e interesse por tecnologia, ao mesmo tempo em que pode haver um professor totalmente inserido no contexto tecnológico.

Precisamos considerar que a familiaridade com as novas tecnologias nem sempre significa utilização eficaz no ensino ou aprendizagem. Tanto jovens quanto adultos estão sujeitos a não "encontrar formas úteis e atraentes de uso pedagógico para as tecnologias de comunicação e informação" (CARLINI; LEITE, 2010, p. 35).

É importante salientarmos que o nosso cérebro é biologicamente preparado para lidar com diferentes abordagens. O lado esquerdo é especializado em reconhecer habilidades como falar, ler, escrever e contar, o que privilegia o foco da escola, mas reprime a interferência das novas tecnologias. Quanto ao lado direito, temos que é

voltado para análise de padrões, solução de problemas, visão ampla do pensamento, intuição, criatividade, conexões e sínteses, expressão emocional, contexto, é capaz de lidar com a complexidade e não linearidade da vida. Enquanto o que o cérebro esquerdo faz pode ser "automatizado", o direito opera interpretativamente, expressando a individualidade e subjetividade da autoria. (DEMO, 2010)

Com isso, vemos que é possível aliar diferentes conhecimentos em sala de aula sem que isso seja prejudicial ao desenvolvimento do aluno. No entanto, para que isso aconteça, é preciso que o professor se permita conhecer o mundo dos estudantes. Isso não significa apenas aceitar suas vontades; significa aprender a equilibrar conhecimento formal e informal. O educador deve, primeiramente, reconhecer que o contexto informal é repletơ de propiciamentos para que a aquisição dessa segunda língua seja mais eficaz. "Propiciamento" é o termo utilizado por Paiva (2009) para traduzir o termo affordance cunhado por Gibson (1986) e abrange tudo aquilo que está disponível no ambiente e pode ser aproveitado pelo aprendiz. Segundo Paiva (2009), “os aprendizes vão em busca de propiciamentos que lhes estimulem a agir, seja pela interação com outros falantes, seja pela emoção estética, seja pela ludicidade, ou pela busca de informação". Isso significa que os aprendizes geralmente buscam em outro ambiente aquilo que não conseguem encontrar na sala de aula para suprir as lacunas mais aparentes. Mais uma vez, temos a demonstração da importância da autonomia na personalidade de um aprendiz de Língua Inglesa. 
Seria muito bom para os alunos que o ensino de Língua Inglesa estivesse aliado às tecnologias digitais de informação e comunicação. O próprio documento oficial atual sobre o ensino de Língua Estrangeira no Brasil, Orientações Curriculares Nacionais, no Capítulo 3, reconhece a importância das novas tecnologias para o ensino e destaca que a "linguagem na comunicação mediada pelo computador oferece muitos exemplos de novos usos de linguagem e da premente necessidade de modificar as concepções anteriores de linguagem, cultura e conhecimento" (BRASIL, 2006, p. 105).

A internet está repleta de influências da Língua Inglesa tanto em sites de relacionamento quanto em jogos on-line, nos quais os usuários mantêm contato com pessoas de outros países. Os jovens são os mais influenciados por essa realidade e isso pode ser positivo, pois o contexto informal, como já dissemos anteriormente, pode oferecer vantagens que o formal provavelmente não poderia.

Nas análises, a seguir, perceberemos melhor a importância do contexto informal na aprendizagem e do incentivo do professor nesse processo. Entenderemos também como certas atitudes desse professor podem inibir a autonomia do aluno e interromper o desenvolvimento do processo de retroação, sobre o qual discorremos na seção anterior.

\section{Metodologia}

Nossa pesquisa se classifica como qualitativa, pois visa entender os fenômenos de acordo com a perspectiva dos alunos participantes. Como postula Demo (2009, p. 146), devemos descartar a dicotomia existente entre quantidade e qualidade, "porque claramente qualidade provém também de bases quantitativas". Nesse sentido, podemos afirmar que, embora com menos ênfase, nossa pesquisa também se classifica como quantitativa.

Além disso, a pesquisa é de cunho etnográfico, pois envolve participação no cotidiano de uma escola municipal regular da cidade de Uberaba/MG através de observações e aplicação de questionários aos alunos do ensino fundamental.

Podemos ainda classificar nossa pesquisa dentro da modalidade participante (SEVERINO, 2007), pois as observações não foram passivas e envolveram interação com os alunos, professora e diretora. Nosso papel de pesquisador compreendeu, portanto, o registro descritivo e análise dos elementos observados.

A escola se localiza no centro da cidade, mas atende alunos tanto de classe 
média alta quanto de classe média baixa. Podemos dizer ainda que a instituição é equipada com tecnologia, sendo a primeira, no município, a ser atendida pelo programa "Um computador por aluno" do governo federal (PROJETO UCA).

A coleta de dados deu-se durante a realização do Estágio Supervisionado obrigatório de Língua Inglesa no Ensino Fundamental no primeiro semestre do ano de 2011. Primeiramente, solicitamos autorização da diretora da escola para realização da pesquisa e, posteriormente, encaminhamos aos pais dos alunos o Termo de Consentimento Livre e Esclarecido, já que todos são menores de idade e não poderiam participar da pesquisa sem autorização dos responsáveis legais.

Foram distribuídos aproximadamente 100 (cem) questionários entre alunos de três turmas da $5^{\mathrm{a}}$ série $\left(6^{\mathrm{o}}\right.$ ano) e três turmas da $7^{\mathrm{a}}$ série $\left(8^{\circ}\right.$ ano). Porém obtivemos apenas 29 (vinte e nove) questionários respondidos e termos assinados. A burocracia foi um grande obstáculo para uma participação maior dos alunøs, pois muitos devolveram o questionário sem o termo ou vice-versa, impedindo-nos de incluí-los na pesquisa.

O questionário aplicado foi desenvolvido pelo GELED (Grupo de Estudos em Linguagem e Educação Digital) e possui questões abertas e fechadas adaptadas por cada integrante do grupo de acordo com as necessidades das pesquisas.

$\mathrm{Na}$ primeira seção do questionário PROCESSO DE APRENDIZAGEM DE LÍNGUAS atribuímos maior importância a duas questões abertas. Na segunda seção USO DE TECNOLOGIA, duas questões fechadas devem ser destacadas: "Se um assunto

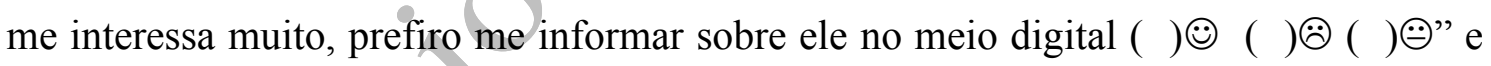
"Utilizo os conhecimentos adquiridos na escola (ex. Inglês) para me comunicar via Internet. ( ) () ( ): ( ):-". Na terceira seção APLICATIVOS POSSIBILITADOS PELO COMPUTADOR E PELA INTERNET, interessa-nos especialmente a última questão aberta.

Após as análises, procuramos entender como se dá a aprendizagem de Língua Inglesa em contextos informais e se a falta de incentivo por parte do professor ao uso dos recursos tecnológicos faz diminuir o interesse do aluno em aprender a língua estrangeira.

\section{Análises}

\subsection{Uso de tecnologia pelos aprendizes e sua inserção em sala de aula}

Iniciamos nossas análises com as questões fechadas do questionário para depois 
compreendermos as respostas dadas nas questões abertas. Nosso foco se restringe a duas perguntas fechadas, como citado anteriormente. A primeira é a seguinte:

Se um assunto me interessa muito, prefiro me informar sobre ele no meio digital Sim: ( ); Não: ( ): Parcialmente: ( ):-

Dos 29 (vinte e nove) participantes, 21 (vinte e um) responderam positivamente, 06 (seis) assinalaram a opção "parcialmente", 01 (um) deixou em branco e apenas 01 (um) respondeu negativamente.

Dentre os que responderam positivamente, 16 (dezesseis) escreveram que têm computador e acesso a internet em casa, sendo que 14 (quatorze) afirmaram em outra questão que participam de alguma rede social como MSN ou Orkut e acessam essas redes com frequência, quase que diariamente. Com isso, temos que a maioria dos participantes de nossa pesquisa são adeptos ao uso da tecnologia como meio de informação e demonstram conseguir perceber a importância do contexto informal de aprendizagem.

A segunda questão fechada que nos interessa é a seguinte:

Utilizo os conhecimentos adquiridos na escola (ex. Inglês) para me comunicar via Internet.

Sim: ( ):- Não: ( ): Parcialmente: ( ):-

Levando em consideração que, no geral, 21 (vinte e um) participantes afirmaram que têm computador e acesso a internet em casa, as respostas para a questão fechada acima nos surpreenderam. Apenas 06 (seis), dentre os que têm acesso à internet, responderam que utilizam ós conhecimentos adquiridos na escola para comunicação virtual; 09 (nove) assinalaram "não" e 06 (seis), "parcialmente". Isso nos faz refletir sobre a aplicabilidade dos conteúdos dados em sala de aula na vida cotidiana dos alunos. Inferimos que a tecnologia é tão constitutiva da vida deles que ela se torna familiar e rotineira, sendo deixada de lado quando o assunto é aprendizagem de conteúdos escolares.

O contexto formal pode ser realmente importante para a aprendizagem de uma segunda língua e não deve ser descartado, mas dizer que ele é o único capaz de promover o contato do aluno com o conhecimento é um equívoco. Para alguns aprendizes, a formalidade na aprendizagem significa quase que uma totalidade de conhecimentos, mas para outros, o contexto formal pode dar origem a um bloqueio, o que não é produtivo para sua vida escolar. Esses alunos não conseguem se desenvolver 
plenamente quando os conteúdos são ensinados de maneira tradicional somente dentro da sala de aula. Eles sentem a necessidade de perceber que esse conteúdo tem alguma relação com sua vida cotidiana ou que aquilo que ele utiliza para diversão pode ser um meio para aprendizagem.

Nesse sentido, salientamos a importância do respeito à individualidade de cada componente do sistema, ou seja, à individualidade de cada aluno presente em sala de aula e, principalmente, a sua autonomia para realizar as escolhas que possam vir a contribuir para o desenvolvimento do processo de ensino e aprendizagem. A desordem, muitas vezes presente no processo de ensino e aprendizagem, pode trazer certa instabilidade tanto para o aprendiz quanto para o educador, mas é essencial para proporcionar oportunidades de conscientização da inerência da autonomia e de construção de uma identidade própria.

Em relação à inserção de tecnologia em sala de aula, apresentamos no questionário algumas opções de aplicativos e solicitamos que escrevessem (0) para nunca usei, (1) para usei uma vez, (2) para usei algumas vezes e (3), uso frequentemente. Após a devida quantificação, chegamos às seguintes respostas:

Quadro 1 - Aplicativos possibilitados pelo computador e pela Internet ${ }^{3}$

\begin{tabular}{|c|c|c|c|c|c|c|c|c|c|c|c|c|c|c|c|c|c|c|c|}
\hline \multicolumn{4}{|c|}{ Mercado Livre } & \multicolumn{4}{|c|}{ Orkut } & \multicolumn{4}{|c|}{ SMS } & \multicolumn{4}{|c|}{ EA Games } & \multicolumn{4}{|c|}{ The Sims } \\
\hline$(0)$ & (1) & (2) & (3) & (0) & (1) & (2) & (3) & $(0)$ & (1) & (2) & (3) & $\overline{(0)}$ & (1) & (2) & (3) & $(0)$ & (1) & (2) & (3) \\
\hline 21 & 3 & 3 & 2 & 2 & 1 & 5 & 21 & 10 & 4 & 7 & 8 & 6 & 3 & 12 & 8 & 6 & 3 & 12 & 8 \\
\hline \multicolumn{4}{|c|}{ Twitter } & \multicolumn{4}{|c|}{ Formspring.me } & \multicolumn{4}{|c|}{ Google Earth } & \multicolumn{4}{|c|}{ MSN Messenger } & \multicolumn{4}{|c|}{ Facebook } \\
\hline (0) & (1) & (2) & (3) & (0) & (1) & (2) & (3) & $(0)$ & (1) & (2) & (3) & (0) & (1) & (2) & (3) & (0) & (1) & (2) & (3) \\
\hline 16 & 3 & 3 & 7 & & & 2 & 3 & 20 & 1 & 8 & 0 & 2 & 3 & 3 & 21 & 11 & 6 & 7 & 4 \\
\hline \multicolumn{4}{|c|}{ Google } & \multicolumn{4}{|c|}{ Youtube } & \multicolumn{4}{|c|}{ Wikipédia } & \multicolumn{4}{|c|}{ Skype } & \multicolumn{4}{|c|}{ Email } \\
\hline (0) & (1) & (2) & (3) & (0) & (1) & (2) & (3) & $(0)$ & (1) & (2) & (3) & (0) & (1) & (2) & (3) & (0) & (1) & (2) & (3) \\
\hline 0 & 0 & 1 & 28 & 0 & 0 & 1 & 28 & 5 & 6 & 11 & 7 & 21 & 5 & 2 & 1 & 6 & 1 & 9 & 13 \\
\hline
\end{tabular}

Analisando o quadro, percebemos que houve maior incidência de respostas (2) e (3) em 09 (nove) dos 15 (quinze) aplicativos. São eles: Orkut, SMS, EA Games, The Sims, MSN Messenger, Google, Youtube, Wikipédia e Email. Isso significa que a

${ }^{3}$ Quadro também apresentado no seguinte artigo do GELED: COSTA, T. B. A influência da ferramenta digital "Google Tradutor" no processo de aprendizagem de língua inglesa. 2011. 
maioria dos participantes tem contato constante com o meio digital através dos aplicativos citados.

Posteriormente, elaboramos o seguinte questionamento:

Você já utilizou algum desses aplicativos na sala de aula? Caso afirmativo, em quais situações (inglês, português, matemática, etc.)? Poderia contar que tipo de atividade o(a) professor(a) desenvolveu com a turma?

No total, 21 (vinte e um) participantes responderam simplesmente "Não" ou "Nunca usei". Apenas 03 (três) responderam "Sim", mas nenhum relato esteve relacionado com Língua Inglesa, como podemos comprovar pela transcrição dos excertos abaixo:

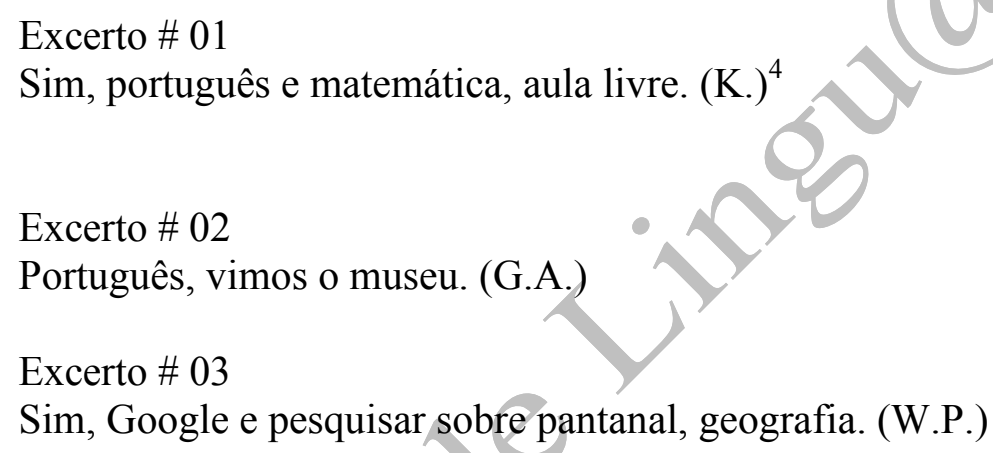

Vale ressaltar que obtivemos maior incidência de respostas positivas para uso dos aplicativos, ao mesmo tempo em que obtivemos mais respostas negativas para uso dos aplicativos em sala de aula. Com isso, percebemos que estes alunos não utilizam tais aplicativos na escola, mas em um contexto informal, têm acesso a eles para outras finalidades.

Outros 03 (três) participantes responderam "Sim", mas não entenderam o real sentido da pergunta e relataram experiências em que utilizaram celulares para navegar na internet sem a devida autorização da professora.

\section{Excerto \# 04}

Matemática - na prova peguei cola pelo celular só que faz muito tempo foi em 2009. (A.M.)

\section{Excerto \# 05}

${ }^{4}$ Os nomes dos participantes desta pesquisa foram preservados, sendo representados através de suas iniciais. A redação original das respostas foi mantida, não tendo sido feita nenhuma correção ortográfica ou gramatical. 
Sim. Em todas mas o professor não estava vendo porque era pelo celular. (M.D.)

Excerto \# 06

Sim eu entro no meu celular nas aulas de história e valores humanos. (J.F.)

Mesmo que essas três respostas não tenham atendido às nossas expectativas, elas demonstram a presença da tecnologia em sala de aula.

As outras 02 (duas) respostas restantes merecem atenção especial, pois estão relacionadas ao "Projeto UCA", cujo objetivo é oferecer um netbook para cada aluno das escolas municipais e modernizar algumas aulas, mantendo contato mais direto com a realidade dos alunos de hoje em dia.

A escola onde coletamos os dados foi a primeira escola da cidade de Uberaba a ser beneficiada pelo projeto. Os netbooks foram entregues no início do ano de 2011, mas já em meados de junho/2011 nenhum aluno havia recebido o material. Portanto, ao perguntarmos sobre o uso dos aplicativos em sala de aula, obtivemos as seguintes respostas:

\section{Excerto \# 07}

Não porque nós não recebeu computadores. (L.S.)

Excerto \# 08

Não recebemos o notebook. (A.C.)

Quando questionamos a professora sobre a demora na entrega dos netbooks para os alunos, ela nos disse que os professores deveriam passar por um treinamento antes, já que a maioria não possuía conhecimento suficiente sobre ferramentas digitais. Percebemos, inclusive, certo receio em sua resposta e uma demonstração de insegurança de quem teme não conseguir dominar aquilo que seus alunos dominam.

Esse é um fator preocupante, pois a resistência por parte do professor em se adequar às necessidades de seus alunos, em aceitar que ainda há muito para se aprender e em se manter aberto para o novo, acaba impondo barreiras maiores para o desenvolvimento do interesse do aprendiz pela matéria. Esse assunto, que será tratado na próxima seção, foi o principal gerador de nossa pergunta de pesquisa.

\subsection{Processo de retroação e irreversibilidade no contexto da sala de aula}

A seção "Processo de Aprendizagem de Línguas" de nosso questionário traz as 
duas principais questões desta parte da análise.

Analisemos cada uma separadamente para então chegarmos a uma conclusão a respeito de nossa pergunta de pesquisa.

Você acha que consegue aprender uma língua estrangeira como inglês sem estar no ambiente escolar? Como você busca o conhecimento fora da sala de aula?

Obtivemos 06 (seis) respostas negativas e 23 (vinte e três) positivas. Dentre as 23 (vinte e três) positivas, 11 (onze) estão relacionadas com a busca de conhecimento pela Internet; 09 (nove) respostas variaram entre "cursos", "professores particulares" e "textos em inglês". Os outros 03 (três) participantes não foram específicos em suas respostas e apenas afirmaram buscar conhecimento fora do ambiente escolar.

Destacamos 03 (três) excertos interessantes dentre as respostas dadas pelos adeptos a internet como meio alternativo de aprendizagem:

Excerto \# 09

$\mathrm{Na}$ internet, em livros de inglês, filmes legendados na TV, no videogame, etc. (I.F.)

\section{Excerto \# 10}

Sim, como disse na pergunta anterior, aprendo na Internet, vendo vídeos de programas em inglês, para saber como se usa o programa, e já aprendo a língua inglesa. (V.H.)

Excerto \# 11

Sim no PCsem jogos, site, na TV desenhos, no PS2 jogos em espanhol, japonês, inglês. (L.F.)

O participante V.H. faz referência a uma resposta dada por ele na questão anterior, o que pode enriquecer nossa argumentação. Vejamos:

Os recursos tecnológicos (jogos on-line, MSN, Orkut...) que você usa no dia a dia influenciam sua aprendizagem de língua estrangeira? Caso afirmativo, de que maneira?

\section{Excerto \# 12}

Sim, pois meu Orkut existe várias palavras em inglês, os jogos online que eu jogo não é do Brasil são dos Estados Unidos, pois converso com jogadores em inglês as vezes. (V.H.)

Entendemos que esses três participantes percebem os propiciamentos presentes no meio digital para aprendizagem de Língua Inglesa, o que já caracteriza um grande avanço tendo em vista o tradicionalismo que ainda permeia as salas de aula do país. No 
entanto, apenas V.H. demonstra realmente efetivar esses propiciamentos, aprimorando seu nível de conhecimento sobre a língua em questão, dado similar ao que foi encontrado por Oliveira, 2011.

Com isso, inferimos que a busca por novas informações no meio digital é prazerosa para os alunos à medida que tal fato acontece por iniciativa própria. Percebemos, pelas respostas apresentadas, que mesmo em momentos de lazer através de MSN, Orkut e jogos diversos, os alunos têm oportunidades para aprender aquilo que talvez não aprenderiam no ambiente da sala de aula.

O incentivo dos professores é um fator importante para instigar esse espírito de autonomia nos aprendizes e foi pensando nisso que elaboramos a próxima pergunta alvo de nossa análise:

Você se sente desmotivado para aprender língua inglesa em razão de alguma atitude negativa do professor, como não te auxiliar em alguma atividade ou não solucionar uma dúvida? Explique.

Ao todo foram 12 (doze) respostas negativas, 15 (quinze) positivas e 02 (duas) em branco. A maioria das respostas negativás ficou restrita a apenas "Não" e as demais especificavam que a falta de auxílio da professora não afetava a aprendizagem devido ao fato de gostarem muito da Língua Inglesa.

Analisemos algumas das respostas positivas:

Excerto \# 13

Sim, pois quando o professor me explica com mal humor, ou quando ele sabe e explica tipo com preguiça eu não faço nenhuma qualquer atividade dessa matéria. (V.H.)

\section{Excerto \# 14}

As professoras tem um desanimo de explicar um pouco a matéria quando o aluno tem dúvida e não é só a de Inglês, as outras também. (B.M.)

\section{Excerto \# 15}

Sim. Porque se ele ou ela não me explicar, vou ficar com dúvidas e se eu ficar com dúvidas depois eu não fíco com vontade de saber mais e desisto. (M.D.)

A resposta de V.H. reflete muito o que presenciamos durante as aulas que observamos no Estágio Supervisionado obrigatório: professores com competência intelectual, mas que pareciam não fazer questão de compartilhar conhecimento ou por acreditarem que aquilo não iria acrescentar nada para a vida do aluno ou simplesmente 
por negligência e falta de interesse em auxiliar o aluno.

No excerto de número treze, B.M. aparentemente responde de acordo com a sua realidade atual, ou seja, ela sente desânimo por parte dos professores não somente nas aulas de Inglês, mas também nas outras. Levando em consideração que B.M. cursa a $5^{\text {a }}$ série $\left(6^{\circ}\right.$ ano) do ensino Fundamental, vemos essa resposta como ainda mais preocupante, tendo em vista que alguma atitude negativa do(a) professor(a) pode marcála negativamente e de maneira significativa.

$\mathrm{O}$ excerto de número quatorze exemplifica o processo de Retroação (BERTALANFFY, 1975; ROSINI, 2006), cujo conceito pode ser transportado para a educação. O processo é espiralar, portanto, temos ação e reação constantemente, como em qualquer sistema complexo. Se a professora não explica a matéria de maneira satisfatória como expôs o participante M.D., o aluno pode ficar com dúvida ou perder o interesse pela matéria e, consequentemente, desistir de aprender ou aprofundar seus conhecimentos.

Explorando o conceito de irreversibilidade (DEMO, 2002), podemos dizer que todo sistema complexo está sujeito à manifestação dessa característica. Com isso, temos que a insatisfação ou desinteresse do aluno pela matéria pode ser irreversível, caso o(a) professor(a) venha a se comportar de maneira descomprometida.

A falta de comprometimento de alguns educadores reflete também no interesse do aluno em buscar conhecimento através de meios alternativos, como o ambiente virtual. Em nossas observações, nos deparamos com algumas situações que exemplificam essa questão.

Como já foi exposto anteriormente, alguns alunos tanto da $5^{\mathrm{a}}$ série $\left(6^{\mathrm{o}}\right.$ ano) quanto da $7^{\text {a }}$ série $\left(8^{\circ}\right.$ ano) traziam dúvidas para serem solucionadas em sala de aula. Como essas dúvidas estavam relacionadas com jogos ou sites da internet, a professora ignorava por acreditar que aquilo não acrescentaria nada para a aprendizagem dos alunos.

Nesse sentido, obtivemos respostas como a que se encontra a seguir para pergunta que estamos analisando.

Excerto \# 16

Sim. Minha professora às vezes que eu faço perguntas ela finge que não me escuta. (C.C)

Essa participante costumava fazer questionamentos a respeito de expressões em 
Língua Inglesa que encontrava na internet, mas a professora, pelo menos em nossa presença, nunca demonstrou prontidão para responder. Por isso, acreditamos que essa resposta de C.C. pode estar relacionada com estes momentos em que ela era ignorada ao inserir o meio digital em sala de aula. Devemos levar em consideração que o nível de proficiência da professora não parecia ser o mais avançado, mas diante de uma situação de questionamento do aluno, acreditamos que ela deveria ao menos demonstrar interesse em pesquisar para poder responder posteriormente.

Retomando o processo de Retroação em sala de aula, podemos dizer que no caso da integração com os recursos tecnológicos, ele acontece da seguinte maneira: o aluno mantém contato com o meio digital como forma de divertimento; ao se deparar com alguma palavra ou expressão em Língua Inglesa que lhe cause dúvida, anota e leva para sala de aula com o intuito de receber auxílio da professora; a professora demonstra interesse, apoio e incentiva o aluno a continuar mantendo sua atenção a tudo que possa lhe trazer conhecimento extra; o aluno, interessado e com a curiosidade aguçada, continua pesquisando novas palavras provenientes da Língua Inglesa nos jogos que participa ou sites que navega e o processo se repete constantemente.

A partir do momento em que a professora ignora o questionamento do aluno ou não reconhece a importância da aprendizagem no contexto informal, ela interrompe o processo natural de Retroação. Os agentes do sistema (aluno e professor) passam a não agir mais em harmonia e esse conflito causa desordem ao meio em questão.

Um exemplo de como um simples gesto de atenção por parte do professor pode devolver a harmonia ao sistema constituído na sala de aula, está na resposta de um dos participantes da pesquisa para a pergunta citada anteriormente. Em uma das aulas, o aluno queria saber o significado de uma frase em inglês que aparecia em seu jogo de cartas. Ele tentou levar o questionamento até a professora, como não obteve êxito, recorreu a nós, estagiárias. Nós prontamente o auxiliamos, o que, provavelmente, gerou a seguinte resposta:

\section{Excerto \# 17}

Sim. Mas tenho sorte, a minha professora é meio brava, mas as assistentes são legais. (A.C.F.)

Isso significa que talvez esse aluno não perca o estímulo para fazer questionamentos ou buscar mais conhecimento sobre a língua. No caso dele, a característica da irreversibilidade deve ser ressignificada, ou seja, devemos 
compreender que a falta de incentivo do professor não determina que o estudante não se motive por outras razões. É preciso ter consciência de que a irreversibilidade estará sempre presente na sala de aula, pois o que acontece não pode retornar no tempo, mas os alunos podem encontrar propiciamentos fora da sala de aula, como defende Paiva (2010).

\section{Considerações Finais}

O presente artigo objetivou responder à seguinte pergunta: Como a falta de incentivo, por parte do professor, à autonomia e à iniciativa do aprendiz ao aprender a Língua Inglesa por meio da internet tende a interromper o processo natural de retroação?

Concluímos, após as análises, que a falta de incentivo do professor à autonomia do aluno tende a interromper o processo em questão e que isso acontece a partir do momento que atitudes negativas e incoerentes do professor (como falta de interesse em responder perguntas, descaso com o conhecimento proveniente do cotidiano do aluno, dificuldades de inserção do contexto informal ao processo de ensino e aprendizagem) afetam significativamente a vida do aluno, fazendo com que ele perca a motivação em aprender determinado conteúdo. Se esse aprendiz sente a falta de incentivo por parte do professor que deveria ser seu maior incentivador na busca por novos conhecimentos, ele pode perder o interesse pela matéria, permanentemente ou definitivamente.

Concluímos ainda que o educador deve trabalhar como um mediador para auxiliar os alunos no reconhecimento das novas tecnologias como inerentes ao processo de aquisição de conhecimento.

A sala de aula como um ambiente de aprendizagem possui a complexidade como característica inerente, principalmente na interação entre professor e aluno. Acreditamos que essa interação deve acontecer de maneira positiva. $O$ aprendiz deve estar aberto para aproveitar o conhecimento compartilhado pelo professor, ao mesmo tempo em que esse educador deve aceitar aquilo que o aluno tem para lhe oferecer. Os mundos de ambas as partes devem conviver em harmonia para que a desordem não se instale de maneira permanente no ambiente, prejudicando o bom andamento do processo de ensino e aprendizagem.

Nossa pesquisa enfrentou algumas limitações em relação à colaboração dos alunos. Muitos até responderam o questionário, mas não levaram o Termo de 
Consentimento assinado pelos pais ou responsáveis. Com isso, pudemos utilizar poucos questionários para nossa análise, o que dificultou um pouco a realização de conclusões mais concretas.

No entanto, essas limitações não impediram nosso desejo de dar continuidade a pesquisa. Surgiu, então, o interesse de realizar os mesmos questionamentos para os alunos do Ensino Médio que, teoricamente, já possuem um contato mais prolongado com a Língua Inglesa. Gostaríamos de entender se eles também sentem falta dos recursos tecnológicos em sala de aula e se as atitudes do(a) professor(a) são relevantes no processo de ensino e aprendizagem.

Outro encaminhamento possível está relacionado ao "Projeto UCA". Seria interessante explorar o uso dos netbooks em sala de aula e analisar se houve alguma mudança na concepção tanto dos alunos quanto da professora em relação à presença dos recursos tecnológicos no contexto formal escolar.

\section{Referências}

BARCELOS, F. A. A. Aprendendo inglês em jogos on-line: um relato sobre nativos digitais. 19f. Trabalho de conclusão de curso (TCC) - Letras, Universidade Federal do Triângulo Mineiro, Uberaba, 2010.

BERTALANFFY, L. Teoria geral dos sistemas. 2. ed. Tradução de Francisco M. Guimarães. Petrópolis: Vozes, 1975. 351 p.

BRASIL. Linguagens, códigos e suas tecnologias. Brasília: Ministério da Educação, Secretaria de Educação Básica, 2006.

CARLINI, A. L.; LEITE, M. T. M. Adolescentes e tecnologias: o aluno nativo digital. IN: CARLINI, A. L.; TARCIA, R. M. L. 20\% a distância e agora?: Orientações práticas para o uso da tecnologia de educação a distância no ensino presencial. São Paulo: Pearson Education do Brasil, 2010.

COSTA, T. B. A influência da ferramenta digital "Google Tradutor" no processo de aprendizagem de língua inglesa. Trabalho de conclusão de curso (TCC) - Letras, Universidade Federal do Triângulo Mineiro, Uberaba, 2011.

CRYSTAL, D. English as a global language. New York: Cambridge University Press, 2003.

DEMO, P. Complexidade e aprendizagem: a dinâmica não linear do conhecimento. São Paulo: Atlas, 2002. 


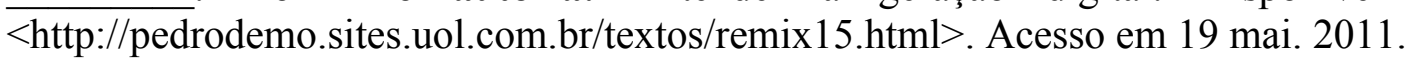

$145-159$.

. Metodologia do conhecimento científico. 1. ed. São Paulo: Atlas, 2009, p.

GIBSON, J. J. The ecological approach to visual perception. Hillsdale: Lawrence Erlbaum Associates, 1986.

HOLLAND, J. Emergence: From Chaos to Order. Helix Books, 1998.

LARSEN-FREEMAN, D. Chaos/Complexity science and second language acquisition. Applied Linguistics. Oxford: Oxford University Press, v. 18, n. 2, 1997.

LARSEN-FREEMAN, D.; CAMERON, L. Complex systems and applied linguistics. Oxford: Oxford University Press, 2008. 287 p.

LORENZ, E. N. Deterministic nonperiodic flow. Journal of the Atmospheric Sciences, v. 20, n. 2, p. 130-141, march 1963.

OLIVEIRA, D. V. De redes sociais a comunidades de prática: um estudo sobre percepção e efetivação de affordances no ambiente on-line. 22f. Trabalho de conclusão de curso (TCC) - Letras, Universidade Federal do Triângulo Mineiro, Uberaba, 2011.

PAIVA, V. L. M. O. Caos, complexidade e aquisição de segunda língua. In: PAIVA, V. L. M. O.; NASCIMENTO, M. (Org.). Sistemas adaptativos complexos: lingua(gem) e aprendizagem. Belo Horizonte: Faculdade de Letras da UFMG, 2009. p. 187-203.

Propiciamento (affordance) e autonomia na aprendizagem de língua inglesa In: LIMA, Diógenes Cândido. Aprendizagem de língua inglesa: histórias refletidas. Vitória da Conquista: Edições UESB, 2010.

PRENSKY, M. Digital natives, digital immigrants. On the Horizon, v. 9, n. 5, 2001. ROSINI, A. M. Metodologia em Sistemas de Informação. In: ROSINI, A. M. As Novas Tecnologias da Informação e a Educação a Distância. São Paulo: Pioneira, 2006, p. $103-116$.

SEVERINO, A. J. Metodologia do Trabalho Científico. São Paulo: Cortez, 2007, p. $117-126$.

Artigo recebido em: 27.09.2012

Artigo aprovado em: 18.12.2012 